\title{
STANDARDIZING OUTPUT-BASED SURVEILLANCE TO CONTROL NON-REGULATED DISEASES OF CATTLE IN THE EU (SOUND-control, COST action-CA17110)
}

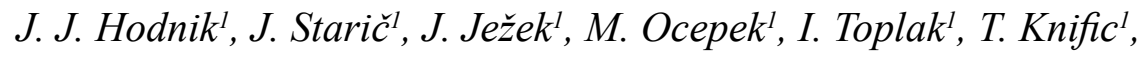 \\ G. J. Gunn' ${ }^{2}$ I. Santman-Berends ${ }^{3}$, C. Correia-Gomes ${ }^{2}$ \\ jaka.hodnik@vf.uni-lj.si
}

${ }^{1}$ University in Ljubljana, Veterinary faculty,

Gerbičeva ul. 60, Ljubljana, 1000, Slovenia

${ }^{2}$ SRUC Epidemiology Research Unit,

An Lòchran, Inverness Campus, Inverness, IV2 5NA, UK

${ }^{3}$ Gezondheidsdienst voor Dieren,

Arnsbergstraat 7, Deventer, 7418 EZ, Netherlands

The European Union (EU) overviews the control, eradication and surveillance of many cattle diseases especially those that are detrimental to animal or human health, cause huge economic losses or are subjected to trade restrictions. Other cattle diseases are left to be controlled by each Member State (MS). However, these diseases can also cause economic losses, which are usually hidden at first glance, as they often have subclinical or chronic courses. Trade of live cattle can introduce those diseases into countries that have already eradicated or have never even had them. Therefore, there is a gap in knowledge of how different EU countries control each disease and what their current disease status is.

A team of 76 veterinarians, epidemiologists, statisticians, economists, sociologists, stakeholders etc. from 30 different countries have come together to participate in an action called Standardizing output-based surveillance to control non-regulated diseases of cattle in the EU (SOUND control) CA17110 funded by COST (European Cooperation in Science and Technology). The aim of the project is to gather information about the different control programmes and produce an output-based framework. Five working groups have been formed. Work group 1 (WG1) aims to gather information on existing control programmes for non-EU regulated cattle diseases in participating countries and produce a list of relevant stakeholders. The focus is on diseases not listed under categories A or B in the new European Animal Health Law. WG2 aims to identify which data are required to serve as input for an output-based framework, and to assess the data availability and quality for each country. WG3 aims to find methods that enable output-based comparison of different control programmes, identify gaps and also evaluate cost-effectiveness, social acceptability and generalizability of those methods. WG4 is entrusted with the development of a joint research agenda about possibilities to combine heterogeneous inputs into an output-based framework that is applicable to a large number of non-regulated cattle diseases. Finally, WG5 will be responsible for the dissemination of knowledge achieved during the SOUND-control action to a wider audience and to encourage the incorporation of an output-base framework both on national and European level. The action has started in 2018 and will end in October 2022.

The objective of the SOUND control action is to explore and implement a widely adaptable output-based framework to substantiate the confidence of freedom and costs-effectiveness in current surveillance, control or eradication programmes for non-regulated cattle diseases in Europe. The results of this project will facilitate safe trade and support the improvement of disease control measures, which is of great importance for the EU agriculture since the cattle sector contributes one third to the total gross production value.

Keywords: BOVINE, CONTROL PROGRAMMES, EUROPE, INFECTIOUS DISEASES, DISEASE MODELLING

The European Union (EU) overviews the control, eradication and surveillance of many cattle diseases especially those that are detrimental to animal or human health, cause huge economic losses or are subjected to trade restrictions. Other cattle infectious diseases (like bovine viral diarrhoea, infectious bovine rhinotracheitis infectious pustular vulvovaginitis, paratuberculosis, etc.) are left to be controlled by each Member State (MS) [7]. However, these diseases can also cause economic losses, which are usually hidden at first glance, as they often have subclinical or chronic courses [4]. They also reduce the welfare of affected animals [3]. Trade of live cattle can introduce those diseases 
into countries/farms that have already eradicated or have never even had them [7].

For notifiable cattle diseases, EU regulations (Regulation (EU) 2016/429, Council Directive 82/894/EEC) [6] are in place to help harmonise requirements for the free status of the animal, herd and/or country. The study design, sampling scheme and type of tests are generally prescribed by EU regulations, so-called "input-based standards". In contrast, "output-based standards" do not prescribe what needs to be done, but rather what must be achieved. Enabling standardised comparison between outputs of Control programmes (CPs) is important in light of intracommunity trade of cattle with potential substantial economic consequences. Some EU countries are implementing regional or national CPs for non-regulated cattle diseases for which, no generally accepted rules or guidelines are currently in place. Consequently, countries are generally developing their own CPs, often with considerable country-level variation in respect to both programme design and implementation [5].

COST (European Cooperation in Science and Technology) is a Horizon 2020 EU funded organization that funds research and innovation networks. COST actions help connect research initiatives across Europe and beyond and enable researchers and innovators to grow their ideas in any science and technology field by sharing them with their peers. COST Actions are bottom-up networks with duration of four years that boost research, innovation and careers [1].

\section{Materials and methods}

SOUND control is currently a team of 76 veterinarians, epidemiologists, statisticians, economists, sociologists, stakeholders etc. from 30 different countries, but other people with relevant expertise and experience (Veterinary science: Veterinary medicine (miscellaneous); Veterinary science: Databases, data mining, data curation, computational modelling; Animal and dairy science: Applied mathematics, statistics, non-computational modelling) may join. SOUND control stands for Standardizing OUtput-based Surveillance to control Non-regulated Diseases of cattle in the EU and is funded by COST. SOUND control aims to use innovative methods for standardizing output-based surveillance to control non-regulated diseases in the EU. Regardless of the heterogeneities in the data, a joint understanding about the requirements and characteristics needed for proof of freedom will be developed. Cost-effectiveness of different control programmes will be compared. SOUND-control will assist with initiatives to explore and implement a widely adaptable, output-based framework to substantiate confidence of freedom from infectious diseases and assess epidemiological and economic equivalence of control efforts. With the new Animal Health Law, it is anticipated that disease control will progressively change towards output-based approaches. SOUND-control will provide requirements and demands for a single general regulatory framework, adaptable to multiple diseases, which aims to enhance the safety of trade [5].

Five working groups have been formed.

- Work group 1 (WG1) aims to identify and reach an agreement on the requirements (both scientific and practical) that should be met by a framework that aims at an objective comparison of the output of CPs for non-regulated cattle diseases in the EU; and to identify the non-regulated cattle diseases for which control, eradication and/or surveillance are currently being conducted in the EU. The framework should be applicable to a large number of diseases, but will initially be designed for a few example diseases with considerable variation between member states (MS). The focus is on diseases not listed under categories A or B in the new European Animal Health Law.

- Work group 2 (WG2) aims to evaluate the availability and quality of the heterogeneous data that is needed as an input for an output-based framework. This will be evaluated at each level of aggregation and for each of the countries involved in the SOUND-control Action.

- Work group 3 (WG3) aims to evaluate existing methods enabling output-based comparison of CPs and identify gaps.

- Work group 4 (WG4) will encourage research initiatives that aim to take the next steps into development of innovative methodologies that tackle the gaps identified in WG3, including mathematic, epidemiologic, economic and social science methods, and facilitate the possibilities for 
short term scientific missions (STSMs) to combine expertise from different research areas.

- Dissemination of knowledge that is achieved during the SOUND-control Action and encouraging the incorporation of an output-based framework both on national and European level will be the obligation of all WG but specifically of Work group 5 (WG5).

The action has started in late 2018 and will end in October 2022 [5].

\section{Results and discussion}

Since the beginning of the action three meetings have been held. The kick off meeting was in Brussels, Belgium (29.10.2018), the second meeting was a WG1 meeting in Porto, Portugal (21.1.2019) and the third meeting in Utrecht, Netherlands was a WG1 workshop as well as WG meetings and a management committee meeting (25-26.3.2019). Two STSMs have already taken place. The main deliverables are going to be an overview of non-EU regulated diseases with control programmes, contact list of relevant stakeholders, handbook describing the different control programmes, review paper comparing methodologies for evaluation of control programmes, SOUND-control website and hopefully an output-based framework for the control of non-regulated cattle disease in the EU [5].

\section{Conclusions}

Surveillance, control or eradication of non-listed cattle diseases in the EU is important because it leads to a reduction in disease burden, improvement in the overall health and welfare of livestock, reduces medicine use and improves sustainability of livestock production. However, for countries that have achieved, or are implementing, control and eradication of these diseases, trade between different regions or countries currently poses a very tangible risk of reintroduction of infections and diseases into susceptible populations [7].

In SOUND-control, the available methods will be evaluated and required improvements and initiatives will be identified to refine existing and developing innovative methods for field application of an output-based framework that is ultimately widely applicable to a large range of cattle diseases in the EU. Transfer of new knowledge will enable countries to learn from each other and increase the probability of success with improved country-level efforts towards surveillance, control or eradication [5].

1. COST: European cooperation in science and technology. Available at: http://www.cost.eu (accessed on April $1^{\text {st }}$, 2019).

2. Council Directive $82 / 894 /$ EEC on the notification of animal diseases within the Community, 1982. Available at: http://data.europa.eu/eli/dir/1982/894/oj

3. Garcia A. B., Shalloo L. Invited review: The economic impact and control of paratuberculosis in cattle. Journal of Dairy Science, 2015, vol. 98, issue 8, pp. 5019-5039. DOI: 10.3168/jds.2014-9241.

4. Martins E.G., Oliveira P., Oliveira B. M., Mendonça D., Niza-Ribeiro J. Association of paratuberculosis sero-status with milk production and somatic cell counts across 5 lactations, using multilevel mixed models in dairy cows. Journal of Dairy Science, 2018, vol. 101, issue 8, pp. 7638-7649. DOI: 10.3168/ jds.2017-13746.

5. MoU: Memorandum of Understanding for the implementation of the COST Action Standardizing output-based surveillance to control non-regulated diseases of cattle in the EU (SOUND-control) CA17110. Available at: https://www.cost.eu/actions/CA17110/\#team (accessed on April 1 $1^{\text {st }}, 2019$ ).

6. Regulation (EU) $2016 / 429$ of the European Parliament and of the Council of 9 March 2016 on transmissible animal diseases and amending and repealing certain acts in the area of animal health ("Animal Health Law").

7. Santman-Berends I. M. G. A., Mars M. H., Van Duijn L., Van den Broek K. W. H., Van Schaik G. A quantitative risk-analysis for introduction of Bovine Viral Diarrhoea Virus in the Netherlands through cattle imports. Preventive Veterinary Medicine, 2017, vol. 146, pp. 103-113. DOI: 10.1016/j.prevetmed.2017.08.003. 